\title{
The Need for Data Contextualization in Urban-Water Systems in Terms of Environmental and Behavioural Health
}

\author{
Panagiotis KATRAKAZAS ${ }^{\mathrm{a}, 1}$, Theodora KALLIPOLITOU ${ }^{\mathrm{a}}$ and Ilias SPAIS

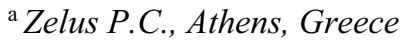

\begin{abstract}
The current paper addresses the need for making scientific knowledge easily accessible, comprehensible, and tailored for citizens, especially in urbanwater habitats, enabling their behavioural change and consequent climate change resilience. It proposes a schema that integrates data from different sources and highlights their relevance to citizens (aiming to raise their awareness), the impact on the citizens' Quality of Life as well as the way they (will have to) perform various activities. Targeted bibliographical research through online digital libraries was conducted to capture the scientific coverage and validation of this need. As an outcome, the complexity and interdependencies of environmental and behavioural health issues growth has been confirmed, and public health programs have begun to identify the need for the integration of data from diverse sources. Therefore, the proposed schema could be used for enabling better design of public health policy making.
\end{abstract}

Keywords. data contextualization, environmental health, urban-water system, locality impact, behavioural engagement

\section{Introduction}

As highlighted by the COVID-19 pandemic [1] there is a pressing need to get a holistic approach towards climate mitigation and adaptation pathways, to understand the effects of anthropogenic activity in local environments where the marine and urban ecosystems are strongly interrelated and drive human activity. This holds especially true for urban water systems, e.g., a port-city, where, despite boosting the economy, there is a negative impact on the environment, hence the health of residents of the surrounding areas $[2,3]$. Living near the port areas is associated with low socioeconomic status, while the environmental pollution caused by port activities increases the risk of developing a number of diseases, including heart and lung diseases, as well as increased stress levels, resulting in negatively affecting the residential Quality-of-Life levels [4].

\section{Methods}

Three digital online libraries (i.e., IEEEXplore, PubMed and ScienceDirect) were used to identify studies of relevant interest to the topic exploration. Targeted bibliographical

\footnotetext{
${ }^{1}$ Corresponding Author, e-mail: p.katrakazas@zelus.gr
} 
research was performed to highlight the different perspectives taken on behavioural, environmental, and public health linkage with respect to data contextualisation needs in these areas. Our results are hereinafter provided.

\subsection{Bridging the gap between environmental, behavioural public health space}

A key factor that contributes to climate related anxiety (the so-called eco-anxiety) is knowing danger is coming but not having any appropriate scripts, skills, or direct agency in place to mitigate it [5]. Two of the key messages for policymakers is a) "to enhance the personal responsibility for people to behave more climate-friendly by providing information about the impact and the consequences of personal behaviour" [6,7] and b) to promote and engage on support for neighbourhood and community-level greening [8]. Complementary to that and given the current Covid-19 crisis, increased need for environmental health services [9] and attention should be given to duty and heedfulness of social justice and environmental health issues, in order to eliminate discrimination against vulnerable populations [10].

As environmental exposures pose an important health determinant [11], public health interventions should take into consideration the links between behavioural aspects and implementation of health in all policies aiming to improve public health. However, given the recent failure of behavioural change approaches given the Covid-19 pandemic [12] and the environmental impact yielded by it, approaches like the one presented by B.M. Stieb et al [13] should be brought into the spotlight, especially when urban-water systems are concerned, as highlighted also by the lack of relevant articles [14].

\subsection{A suggestion towards a multi-level approach schema}

Considering the different perspectives and the different levels of complexity among portcities, we need to take into consideration the micro-, meso- and macro- system perspective, including, but not limited to, each port-city's different governance mechanisms, competitiveness, spatial and strategic interdependencies, and economical role, complementarily to the Sustainable Development Goals (SDGs). In more detail:

The micro-level refers to the extraction of relationships affecting the inner systemic elements of the port-city. To do so, bringing an advanced behavioural services framework for the transition of the port-city actors' activities using geospatial data insights and end users' input (e.g., a way of analyzing the characteristics of locality in urban-water systems can be outlined. The Locality Pattern System [15] or simple perception mapping [16] can be applied and adapted in the planning and design processes, resulting in future-orientated localities with biodiversity in mind. The establishment of these mechanisms will enable and facilitate the inclusion and participation of port-city end users in tackling the struggles of their own area (locality characterization) and the research-based design of actions that can be implemented at different levels (i.e., consumption and lifestyle) for the public health policy makers.

The meso-level tackles the conflicting nature of port-city by examining the port and city entities. Promotion of a constructive and evidence-based dialogue among these two systemic elements can be achieved by deploying related services for monitoring air emissions, urban built-up and public health footprint of port-city activities (e.g. like the ones used in [17] and [18]. These services can provide open, comprehensible, and wide access information and recommendations for action to the key users and stakeholders for an interactive and meaningful decision-support. 
Finally, the macro-level examines the interrelation of the port-city as an entity located in a global map, therefore it is about promoting knowledge and information collection, sharing and management from natural, social, engineering, and maritime sciences via a high-level knowledge system, so as to increase the socioeconomic, health and climate resiliency of port-city environments in a multidisciplinary and systemic approach. Adaptation of existing multi-level frameworks [19-21] will allow a better monitoring of the environmental health and behaviour engagement, in accordance with the Sustainability Development Goals (SDGs) set for 2030, which point towards implementing a sustainable development of the society.

\section{Discussion: The need for data contextualization}

Collecting data and observing biodiversity behaviour in urban-water areas is more than crucial for identifying correlations and quantifying the impact of observed changes on people's health. The schema will facilitate the monitoring of the relative active level of urban-water system development and the anthropogenic activity levels, including industrial and spatial integration to identify and characterize the urban-water habitation and correlation factors. A better monitoring of these influencing parameters and action mechanisms from a dynamic and regional comparison perspective among the heterogeneous flows of actors, assets and structures involved, will test what is already known about mitigation and adaptation behaviours being more engaging for citizens with high environmental awareness or concern, versus those with lower awareness or concern.

This will provide the basis for "a breadth of rationales for actions bringing joint mitigation and adaptation benefits - and the provision of practical information to help citizens modify existing practices" [8]. Contextualizing information about air, water, noise and other types of environmental disturbance will reinforce and build on emergent insights on the relation between each citizen's practices (whether they are individuals or organizations living and operating in it) and the wider social and cultural context. It will also question the extent to which extant social and cultural practices within an urbanwater area may be able to cope with the pace and extent of climate change and its consequences on people's wellbeing. In practical terms, this will lead to a holistic vision of the biogeography of the urban-water systems helping to generate prospective proposals for localized management and long-term transformation.

However, data contextualization in this context will not be easy as opposing social, political and public health processes have to be faced. As technological progress and attractions of urban-water habitats will sustain migration into them, their infrastructure will not or hardly be able to keep up with population increase. Crowdedness, unemployment, pollution, health and security risks will hinder the pathway towards a sustainable development. Therefore, having a holistic view of the urban-water habitat elements interactions, strengthening any stabilising interrelations and gaining data insights is more than necessary in the operation of the global society system, especially for providing the missing feedbacks, meaning the creation of a schema, like the one proposed in the current paper, which assists towards the successful coverage of common human wellbeing and their micro-, meso- and exo-systemic interests. 


\section{References}

[1] Sharifi A, Khavarian-Garmsir AR. The COVID-19 pandemic: Impacts on cities and major lessons for urban planning, design, and management. Sci Total Environ. 2020 Dec 20;749:142391.

[2] Manisalidis I, Stavropoulou E, Stavropoulos A, Bezirtzoglou E. Environmental and Health Impacts of Air Pollution: A Review. Front Public Health [Internet]. 2020 Feb 20 [cited 2020 Nov 17];8. Available at: https://www.ncbi.nlm.nih.gov/pmc/articles/PMC7044178/.

[3] European Court of Auditors. Air pollution: our health still insufficiently protected [Internet]. LU: Publications Office; 2018 [cited 2021 Jan 10]. (Special report No (European Court of Auditors. Online). Available at: https://data.europa.eu/doi/10.2865/80097.

[4] European Commission. Directorate General for the Environment., University of the West of England (UWE). Science Communication Unit. Links between noise and air pollution and socioeconomic status. [Internet]. LU: Publications Office; 2016 [cited 2020 Nov 17]. Available at: https://data.europa.eu/doi/10.2779/200217.

[5] Ingle HE, Mikulewicz M. Mental health and climate change: tackling invisible injustice. Lancet Planet Health. 2020 Apr 1;4(4):e128-30.

[6] Jakučionytė-Skodienè M, Liobikienė G. Climate change concern, personal responsibility and actions related to climate change mitigation in EU countries: Cross-cultural analysis. J Clean Prod. 2021 Jan 25;281:125189.

[7] Odou P, Schill M. How anticipated emotions shape behavioral intentions to fight climate change. J Bus Res. 2020 Dec 1;121:243-53.

[8] Kondo K, Mabon L, Bi Y, Chen Y, Hayabuchi Y. Balancing conflicting mitigation and adaptation behaviours of urban residents under climate change and the urban heat island effect. Sustain Cities Soc. 2021 Feb 1;65:102585.

[9] Rodrigues MA, Silva MV, Errett NA, Davis G, Lynch Z, Dhesi S, Hannelly T, Mitchell G, Dyjack D, Ross KE. How can Environmental Health Practitioners contribute to ensure population safety and health during the COVID-19 pandemic?. Safety Science. 2021 Apr 1;136:105136.

[10] Aschner M, Paoliello MMB, Tsatsakis A, Bowman AB, Dorea JG, Hartung T, et al. Social injustice in environmental health: A call for fortitude. Environ Res. 2021 Mar 1;194:110675.

[11] Rojas-Rueda D, Morales-Zamora E, Alsufyani WA, Herbst CH, AlBalawi SM, Alsukait R, et al. Environmental Risk Factors and Health: An Umbrella Review of Meta-Analyses. Int J Environ Res Public Health. 2021 Jan;18(2):704.

[12] West R, Michie S, Rubin GJ, Amlôt R. Applying principles of behaviour change to reduce SARS-CoV2 transmission. Nat Hum Behav. 2020 May;4(5):451-9.

[13] Stieb DM, Huang A, Hocking R, Crouse DL, Osornio-Vargas AR, Villeneuve PJ. Using maps to communicate environmental exposures and health risks: Review and best-practice recommendations. Environ Res. 2019 Sep 1;176:108518.

[14] Zheng Y, Zhao J, Shao G. Port City Sustainability: A Review of Its Research Trends. Sustainability. 2020 Jan; 12(20):8355.

[15] Prominski M, Busche K. Locality Pattern Systems as Design Tools for Water-Related Open Spaces. In: Wang F, Prominski M, editors. Water-Related Urbanization and Locality: Protecting, Planning and Designing Urban Water Environments in a Sustainable Way [Internet]. Singapore: Springer; 2020 [cited 2021 Sep 9]:3-26. Available at: https://doi.org/10.1007/978-981-15-3507-9_1.

[16] Delphine, Busquet M, Santpoort R, Witte P, Spit T. Living on the edge: Identifying challenges of port expansion for local communities in developing countries, the case of Jakarta, Indonesia. Ocean Coast Manag. 2019 Apr 1;171:119-30.

[17] Andrade MJ, Costa JP, Blasco López J. 3DPortCityMeasure: Methodology for the Comparative Study of Good Practices in Port-City Integration. Sustainability. 2020 Jan;12(3):880.

[18] Liu J, Kong Y, Li S, Wu J. Sustainability assessment of port cities with a hybrid model-empirical evidence from China. Sustain Cities Soc. 2021 Dec 1;75:103301.

[19] Cao L, Tang Y, Cai B, Wu P, Zhang Y, Zhang F, et al. Was it better or worse? Simulating the environmental and health impacts of emissions trading scheme in Hubei province, China. Energy. 2021 Feb 15;217:119427.

[20] Alvarez CH, Evans CR. Intersectional environmental justice and population health inequalities: A novel approach. Soc Sci Med. 2021 Jan 1;269:113559.

[21] Milojevic-Dupont N, Creutzig F. Machine learning for geographically differentiated climate change mitigation in urban areas. Sustain Cities Soc. 2021 Jan 1;64:102526. 